\title{
Extended P21-Based Benchmarking
}

\author{
Zhiguang Cheng ${ }^{1}$, Behzad Forghani ${ }^{2}$, Tao Liu ${ }^{1}$, Yana Fan ${ }^{1}$, Lanrong Liu ${ }^{1}$ \\ ${ }^{1}$ Institute of Power Transmission and Transformation Technology, Baobian Electric Co., Ltd, Baoding, China \\ ${ }^{2}$ Infolytica Corporation, Place du Parc, Montreal, Canada
}

Email address:

emlabzcheng@yahoo.com (Zhiguang Cheng), forghani@infolytica.com (B. Forghani)

\section{To cite this article:}

Zhiguang Cheng, Behzad Forghani, Tao Liu, Yana Fan, Lanrong Liu. Extended P21-Based Benchmarking. International Journal of Energy and Power Engineering. Special Issue: Numerical Analysis, Material Modeling and Validation for Magnetic Losses in Electromagnetic Devices. Vol. 5, No. 1-1, 2016, pp. 1-11. doi: 10.11648/j.ijepe.s.2016050101.11

\begin{abstract}
This paper highlights two important aspects of the electromagnetic field modeling and simulation when used for industrial applications, namely the application based benchmarking activities and the magnetic material modeling. It emphasizes the relationship between the two, and briefly reviews the recent progress in extending the TEAM (Testing Electromagnetic Analysis Methods) Problem 21 Family (P21) and the related modeling results, and proposes a new benchmarking project which includes the upgraded benchmark models that can handle extreme excitations, i.e. current sources with a DC bias, as well as multiple harmonics.
\end{abstract}

Keywords: Extended Benchmarking, Extreme Excitation, Finite Element, Industrial Application, Magnetic Flux, Magnetic Loss, Problem 21 Family (P21), Working Magnetic Property Modeling

\section{Introduction}

The effectiveness of the numerical modeling and simulation is dependent on the electromagnetic analysis method, computational software being used, and access to sufficient material property data. Consequently, the development and validation of both the numerical computation method and the material property modeling, under working conditions, are of great interest.

In order to validate the numerical modeling methods, since 1985, the international COMPUMAG (the biennial conference on the computation of the electromagnetic fields) society (ICS) has paid great attention to organizing the TEAM activities worldwide, in order to test and compare the electromagnetic analysis methods, and has established a series of benchmark problems that are now widely used in the computational electromagnetics community [1]. Meanwhile, the IEEE Standard for validation of computational electromagnetics computer modeling and simulations has also been issued [2]. The authors have devoted a lot of their work to the engineering-oriented TEAM activities for many years [3-15], have proposed an engineering-oriented benchmark family of problems, Problem 21[1,3,4], and have updated it three times since 1993, which has been of interest to many scientists and engineers up to now.

On the other hand, more advanced material modeling techniques have been investigated systematically, involving extreme magnetization conditions [16]. As a result, there has been significant progress in the efficient design of electromagnetic devices [17-20]. However, so far, what is widely used in industrial applications is the standard one-dimensional B-H curves, obtained from either the Epstein frame or the single sheet tester (SST). Of course, magnetic properties change according to the working conditions, e.g. they can vary with the frequency, the temperature, and the stress action. Therefore, it is necessary to validate the magnetic property data under the same working conditions that the device is subjected to.

In very large electromagnetic devices, for example a EHV (extra high voltage) power transformer, the reduction of the stray-field loss, produced by the leakage flux from the transformer winding and heavy current leads, and the protection against unallowable loss concentrations, and then the resulting local overheating have become more and more significant[21-27]. Various types of power frequency shields are widely utilized to effectively save energy and ensure a reliable operation. In addition, the various shields can change and control the global distribution of the 3-D electromagnetic field inside a large electromagnetic device. It is important to accurately model and estimate the multi-shielding effects and optimize the shielding configurations at the electromagnetic design stage $[14,22,23]$. 
The purpose of this paper is to focus on the engineeringoriented benchmarking and the application-based magnetic material modeling in electromagnetic devices, to examine the effect of the variation in the different B-H representations used in different solvers on the iron loss and flux in GO (grain-oriented) silicon steel sheets. In addition, the modeling, simulation and validation, under extreme excitations, as a new benchmarking project, is also proposed in this paper [28].

\section{Problem 21 Family and Selected Benchmarking Results}

The electromagnetic and thermal field problems in large electromagnetic devices are usually very complicated, involving multi-physic field coupling, multi-scale (very thin sheet/penetration depth and very large bulk) configurations, and multi-materials subjected to varying working conditions. In order to obtain an effective solution, the strict validation of the analysis method and software, to be used for solving such complex field problems, is certainly needed. However, it is impossible to do that via a large real electromagnetic device. Therefore, the verification based on the engineering-oriented benchmark models becomes the best and most practical way.

\subsection{TEAM Problem 21 Family}

To investigate the stray-field loss problems in electromagnetic devices, a benchmark family, TEAM Problem 21, consisting of 16 benchmark models, has been well established (the definition of Problem 21, v.2009, can be found at www.compumag.org/TEAM)[1]. See Table 1.

Table 1. TEAM Problem 21 Family (V.2009).

\begin{tabular}{|c|c|c|c|c|}
\hline Member & Models & Electromagnetic features & Industry background & Proposed at \\
\hline $\mathrm{P} 21^{0}$ & $\begin{array}{l}\mathrm{P} 21^{0}-\mathrm{A} \\
\mathrm{P} 21^{0}-\mathrm{B}\end{array}$ & $\begin{array}{l}\text { 3-D nonlinear eddy current and hysteresis } \\
\text { model with multiply connected regions. }\end{array}$ & $\begin{array}{l}\text { Solid magnetic components models, e.g., power } \\
\text { transformer tank or other solid parts. }\end{array}$ & $\begin{array}{l}\text { TEAM-Miami, USA, } \\
1993 .\end{array}$ \\
\hline $\mathrm{P} 21^{\mathrm{a}}$ & $\begin{array}{l}\mathrm{P} 21^{\mathrm{a}}-0 \\
\mathrm{P} 21^{\mathrm{a}}-1 \\
\mathrm{P} 21^{\mathrm{a}}-2 \\
\mathrm{P} 21^{\mathrm{a}}-3\end{array}$ & $\begin{array}{l}\text { 3-D linear eddy current model with multiply } \\
\text { connected regions. }\end{array}$ & $\begin{array}{l}\text { Slotted solid plate models, e.g., core tie-plates in } \\
\text { power transformers. }\end{array}$ & $\begin{array}{l}\text { TEAM-Yichang, } \\
\text { China, } 1996 .\end{array}$ \\
\hline \multirow{2}{*}{$\mathrm{P} 21^{\mathrm{b}}$} & $\begin{array}{l}\mathrm{P} 21^{\mathrm{b}}-\mathrm{MN} \\
\mathrm{P} 21^{\mathrm{b}}-2 \mathrm{M} \\
\mathrm{P} 21^{\mathrm{b}}-2 \mathrm{~N}\end{array}$ & $\begin{array}{l}\text { 3-D nonlinear eddy current and hysteresis } \\
\text { model with magnetic or/and non-magnetic } \\
\text { steel plates separately placed. }\end{array}$ & $\begin{array}{l}\text { Hybrid steel structure models with magnetic and } \\
\text { non-magnetic material aiming to reduce }\end{array}$ & $\begin{array}{l}\text { IEE CEM, } \\
\text { Bournemouth, UK, } 2002 .\end{array}$ \\
\hline & $\begin{array}{l}\mathrm{P} 21^{\mathrm{b}}-\mathrm{MNM} \\
\mathrm{P} 21^{\mathrm{b}}-\mathrm{NMN}\end{array}$ & $\begin{array}{l}\text { 3-D nonlinear eddy current and hysteresis } \\
\text { model with magnetic and non-magnetic steel } \\
\text { plates welded together. }\end{array}$ & $\begin{array}{l}\text { stray-field loss, also can be seen in power } \\
\text { transformer tank. }\end{array}$ & ACES, Miami, USA, 2006. \\
\hline $\mathrm{P} 21^{\mathrm{c}}$ & $\begin{array}{l}\mathrm{P} 21^{\mathrm{c}}-\mathrm{M} 1 \\
\mathrm{P} 21^{\mathrm{c}}-\mathrm{M} 2 \\
\mathrm{P} 21^{\mathrm{c}}-\mathrm{EM} 1 \\
\mathrm{P} 21^{\mathrm{c}}-\mathrm{EM} 2\end{array}$ & $\begin{array}{l}\text { Magnetic shielding and electromagnetic } \\
\text { shielding models: } 3-D \text { nonlinear eddy current } \\
\text { and hysteresis model with anisotropic } \\
\text { lamination. }\end{array}$ & $\begin{array}{l}\text { Magnetic shunt and electromagnetic barriers } \\
\text { models under low frequency, } \\
\text { Widely used in power transformers. }\end{array}$ & $\begin{array}{l}\text { Compumag-Shenyang, } \\
\text { China, } 2005 .\end{array}$ \\
\hline
\end{tabular}

All the member models of Problem 21 Family come from typical structures found in large power transformers, each presenting a different electromagnetic behavior. The engineering-oriented benchmarking activities have the following goals:

\section{(a) Test electromagnetic analysis methods}

According to the original motivation of benchmarking (TEAM), Problem 21 works for testing and comparing the electromagnetic analysis methods and the developed computation software, as well as the commercial software being used.

\section{(b) Verify computation models}

It is important to build a correct numerical computation model that can take into account the nonlinearity, the electric and/or magnetic anisotropy of the material, the skin effect and loss concentration in components, allowing for a reasonable simplification for reducing the computational cost in large scale electromagnetic analysis and design.

(c) Detail the field behavior of typical product structure

Problem 21 is engineering-oriented, including power transformer tank, core-plate, and shielding models. The detailed modeling of the stray field loss generated in different components and the electromagnetic field distributions are helpful in improving the product design.

Table 2. Brief summary of P21-based modeling.

In the iron-loss calculation, the hysteresis loss component and the nonlinearity of the magnetic steel must be accounted ( $\mathrm{P} 21^{0}$

P2 $1^{\circ} \quad$ includes Model A and Model B, i.e., P2 $1^{\circ}-\mathrm{A}$ and P2 $1^{\circ}$-B). The practical calculation method of hysteresis loss and the measured hysteresis loss curves are available $[1,7]$.

The satisfied results of eddy current losses in non-magnetic steel

P21 a can be achieved using different 3-D analysis methods based on different potential sets, even with coarse mesh in non-magnetic components, but 2-D results is not available[4,9,33].

The detailed examination and comparison of both the total loss

$\mathrm{P} 21^{\mathrm{b}}$ and the loss concentration in the hybrid steel plate structure are of importance to improve the product design [10].

The evaluations of the power loss and magnetic flux inside both

$\mathrm{P} 21^{\mathrm{c}}$ electromagnetic and magnetic shields, as well as that of the separation-type shields, are given $[12,13]$.

Both the iron loss and magnetic field inside the GO silicon steel

P2 $1^{\mathrm{d}}$ lamination with different excitation patterns, and the additional iron loss induced by normal magnetic flux are detailed [4-6].

(d) Benefit to large-scale numerical modeling

A benchmark model is different from a large 
electromagnetic device, yet the benchmarking results are useful for solving the large-scale field problems, by simplifying the real problem, the treatment of material properties, and the choice of the solvers.

Table 2 shows a P21-based benchmarking note, which is expected to be helpful for the numerical modeling and computation in electromagnetic devices.

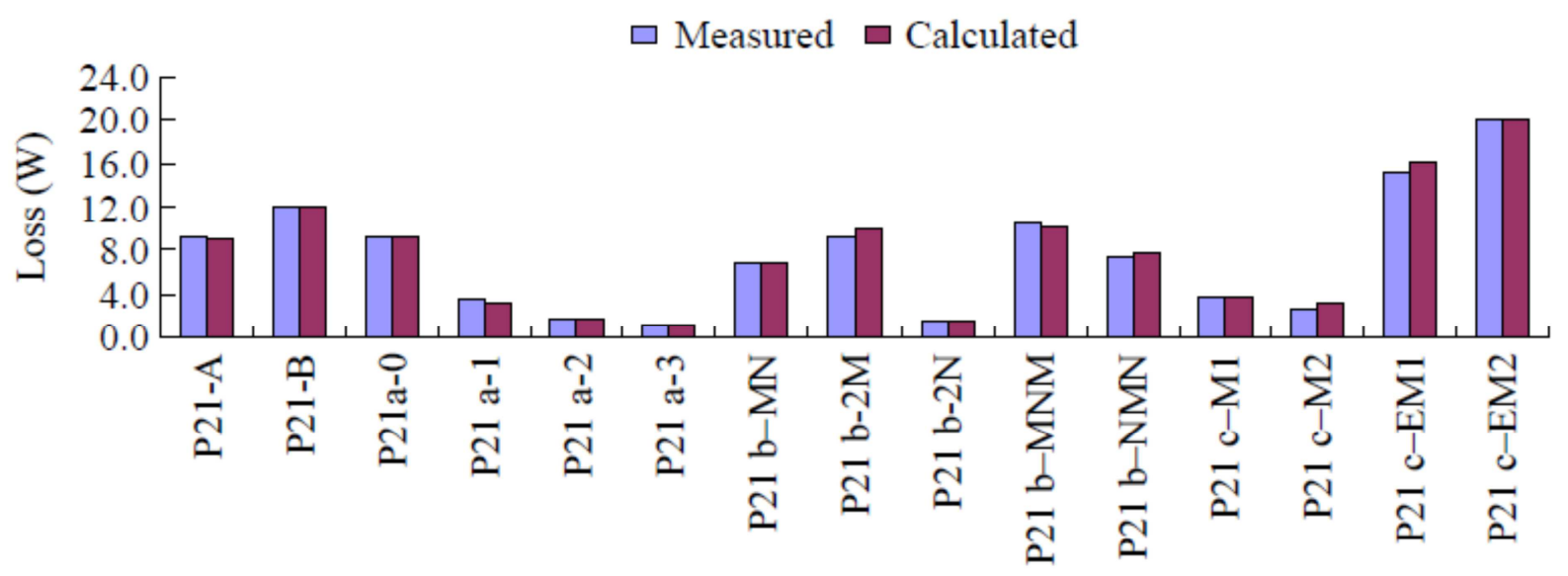

Models

Figure 1. Loss spectrum of Problem 21 Family (with rated excitation condition of 10A, 50Hz).
In version 2009 of Problem 21 Family, the rated exciting current of $10 \mathrm{~A}(\mathrm{rms}, 50 \mathrm{~Hz})$ was upgraded to 50A. As a typical benchmarking result, the measured and calculated results of both the iron loss and magnetic flux inside the magnetic plate for $\mathrm{P} 21^{0}$-B are shown in Table 3 and Table 4 $[1,4]$.

Table 3. Iron loss inside magnetic steel $\left(P 21^{0}-B\right)$

\begin{tabular}{llll}
\hline $\begin{array}{l}\text { Exciting } \\
\text { currents } \\
(\mathbf{A}, \mathbf{r m s}, \mathbf{5 0 H z})\end{array}$ & Measured(W) & $\begin{array}{l}\text { Calculated }(\mathbf{b y} \\
\left.\boldsymbol{A}_{\boldsymbol{r}}-\mathbf{V}-\boldsymbol{A}_{\boldsymbol{r}}\right) \mathbf{P}_{\text {calc. }}(\mathbf{W})\end{array}$ & $\begin{array}{l}\left(\mathbf{P}_{\text {calc. }}-\mathbf{P}_{\text {meas. }}\right) / \\
\mathbf{P}_{\text {meas. }}(\mathbf{\%})\end{array}$ \\
\hline 5 & 3.30 & 3.30 & 0.0 \\
10 & 11.97 & 12.04 & 0.6 \\
15 & 26.89 & 27.12 & 0.9 \\
20 & 49.59 & 50.92 & 2.7 \\
25 & 82.39 & 84.78 & 2.9 \\
30 & 123.70 & 128.67 & 4.0 \\
35 & 179.10 & 183.15 & 2.3 \\
40 & 248.00 & 250.45 & 1.0 \\
45 & 330.00 & 330.91 & 0.3 \\
50 & 423.00 & 425.07 & 0.5 \\
\hline
\end{tabular}

Table 4. Flux inside magnetic steel $\left(P 21^{0}-B\right)$.

\begin{tabular}{|c|c|c|c|}
\hline $\begin{array}{l}\text { Exciting } \\
\text { currents } \\
(\mathbf{A}, \mathbf{r m s}, \mathbf{5 0 H z}) \\
\end{array}$ & $\begin{array}{l}\text { Measured } \\
\Phi_{\text {meas. }}(\mathbf{m W b})\end{array}$ & $\begin{array}{l}\text { Calculated (by } \\
\left.A_{r}-\mathrm{V}-A_{r}\right) \Phi_{\text {calc. }} \\
(\mathrm{mWb})\end{array}$ & $\begin{array}{l}\left(\Phi_{\text {calc. }}-\boldsymbol{\Phi}_{\text {meas. }}\right) / \\
\Phi_{\text {meas. }}(\%)\end{array}$ \\
\hline 5 & 0.158 & 0.151 & -4.12 \\
\hline 10 & 0.318 & 0.306 & -3.86 \\
\hline 15 & 0.478 & 0.458 & -4.13 \\
\hline 20 & 0.618 & 0.605 & -1.98 \\
\hline 25 & 0.770 & 0.750 & -2.66 \\
\hline 30 & 0.936 & 0.890 & -4.90 \\
\hline 35 & 1.064 & 1.024 & -3.76 \\
\hline 40 & 1.206 & 1.152 & -4.48 \\
\hline 45 & 1.357 & 1.276 & -5.97 \\
\hline 50 & 1.486 & 1.396 & -6.06 \\
\hline
\end{tabular}

\subsection{Selected Benchmarking Results}

A number of P21-based benchmarking results have been presented by the authors and other researchers worldwide [4]. A summarized loss calculation results of Problem 21 Family is shown in Fig. 1 [9].
Table 3 and Table 4 show that the 3-D electromagnetic solver based on potential set $A_{r}-V-A_{r}$ [29, 33], developed by the authors, provides good results for both the iron loss and flux under different exciting currents, agreeing well with the measured results.

Table 5 shows that the 3-D eddy current analysis for $\mathrm{P} 21^{\mathrm{a}}$, using different methods based on $A_{r}-V-A_{r}$ and $T-\varphi-\varphi$ potential sets [29-33], also provides good results, but the 2-D calculated results are not available.

Table 5. Eddy currents losses in non-magnetic steel $\left(P 21^{a}\right)$.

\begin{tabular}{llllll}
\hline \multirow{2}{*}{ Models } & \multirow{2}{*}{ Meas. $(\mathbf{W})$} & \multicolumn{3}{l}{ 3-D $(\mathbf{W})$} & \multirow{2}{*}{ 2-D (W) } \\
\cline { 3 - 5 } & & $\mathbf{T}-\boldsymbol{\varphi}-\boldsymbol{\varphi}$ & $\mathbf{A}_{\mathbf{r}}-\mathbf{V}-\mathbf{A}_{\mathbf{r}}$ & $\mathbf{A - V}$ & \\
\hline P21 ${ }^{\mathrm{a}}-0$ & 9.17 & 9.50 & 9.31 & 9.22 & 14.75 \\
P21 $^{\mathrm{a}}-1$ & 3.40 & 3.37 & 3.34 & 3.35 & 6.23 \\
P21 ${ }^{\mathrm{a}}-2$ & 1.68 & 1.67 & 1.66 & 1.68 & 3.07 \\
P21 ${ }^{\mathrm{a}}-3$ & 1.25 & 1.15 & 1.14 & 1.15 & 1.86 \\
\hline
\end{tabular}

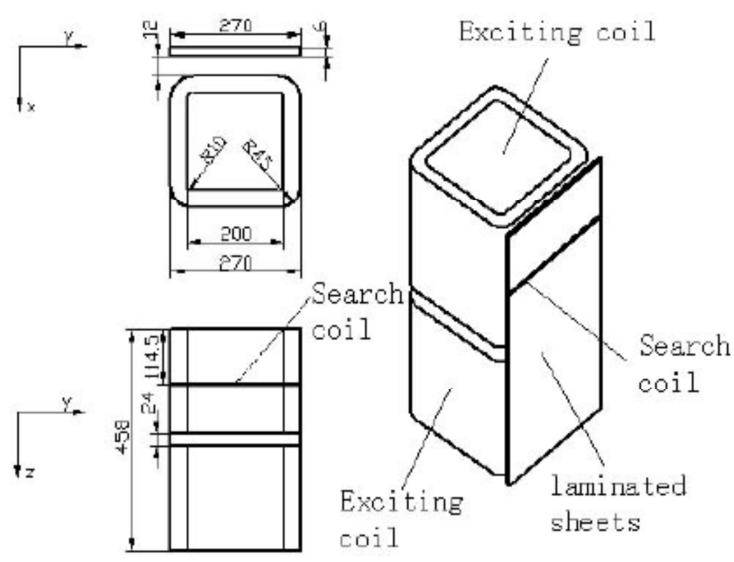

(a) P21 - M1 


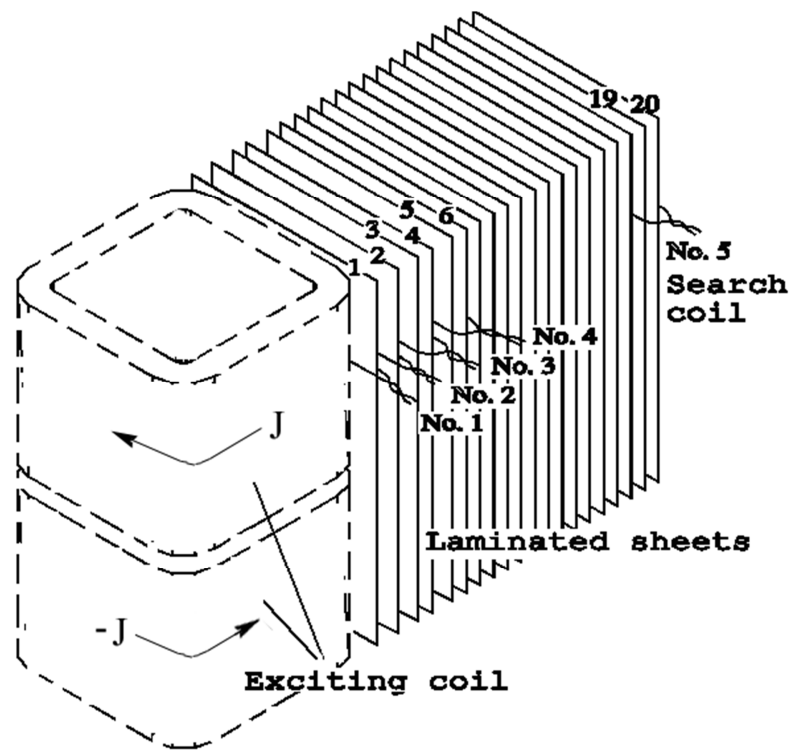

(b) Location of search coils(sketch)

Figure 2. Measurement of flux densities inside sheet.

In order to investigate the iron loss and magnetic flux densities in the laminated sheets, a very simplified model, P2 ${ }^{\mathrm{d}}-\mathrm{M}$ of Problem 21 Family, as shown in Fig. 2(a), has been proposed, which enables us to accurately calculate and measure the loss and the flux within one sheet [11-13], as shown in Fig. 2(b).

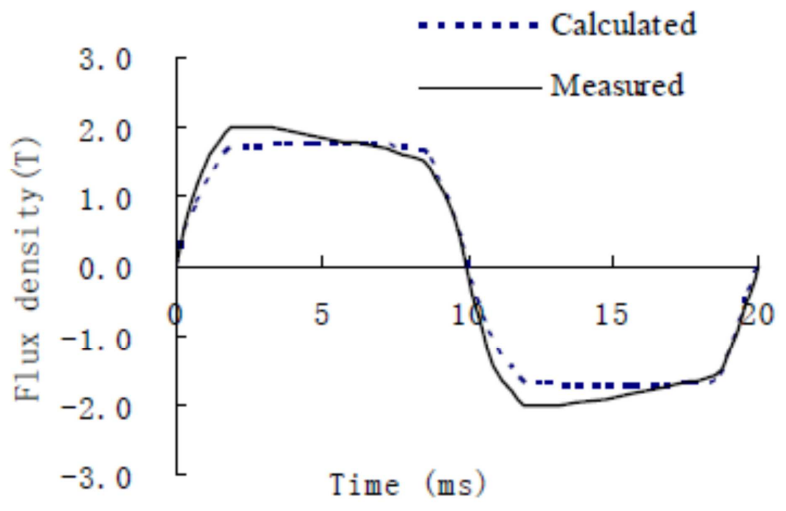

(a) no.1

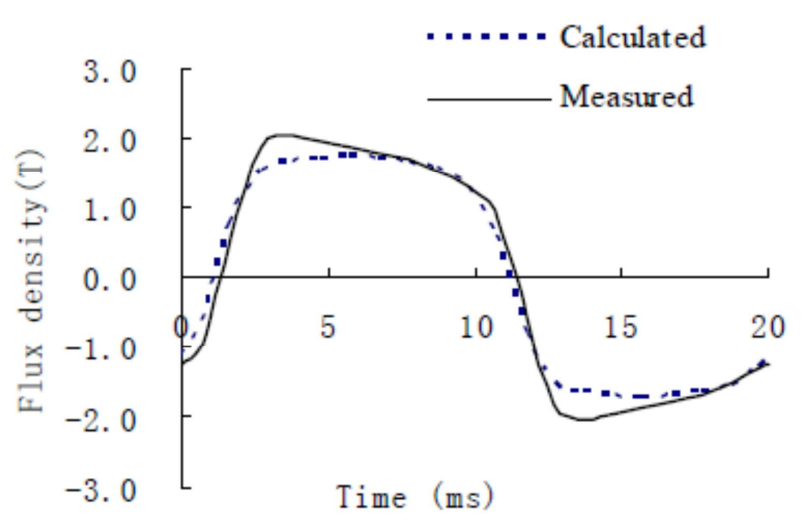

(b) no. 2

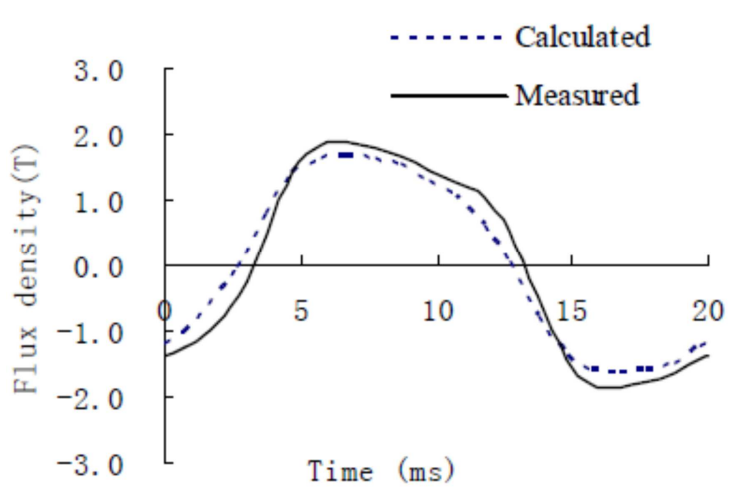

(c) no. 3

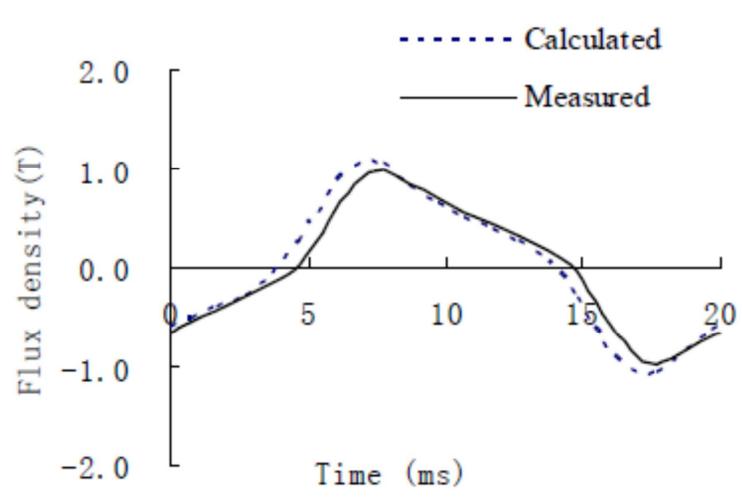

(d) no.4

Figure 3. Waveforms of flux densities inside lamination -layes(exciting currents: $25 \mathrm{~A}, \mathrm{rm}, 50 \mathrm{~Hz}$ ).

The measured and calculated waveforms of the flux densities inside different sheet-layers (from no. 1 to no.4) at the exciting current of $25 \mathrm{~A}(\mathrm{rms}, 50 \mathrm{~Hz})$ are shown in Fig. 3 . The waveforms of flux densities inside the laminated sheets are distorted at different levels and the measured and calculated results agree well.

Note that in the current version of Problem 21 (V.2009, posted on the ICS website, www.compumag.org), the exciting currents have a sinusoidal waveform. The latest extension to the Problem 21 Family can handle the extreme excitation condition, i.e., the electromagnetic components of the member models of Problem 21 are excited by a DC-biased AC supply which may contain a number of harmonics [28]. Table 6 shows two newly proposed models.

Table 6. New upgraded models with extreme excitations.

\begin{tabular}{|c|c|c|c|}
\hline $\begin{array}{l}\text { Proposed } \\
\text { models }\end{array}$ & $\begin{array}{l}\text { Electromagnetic } \\
\text { features }\end{array}$ & $\begin{array}{l}\text { Industry } \\
\text { background }\end{array}$ & Remarks \\
\hline $\mathrm{P} 21^{0}-\mathrm{B}^{+}$ & $\begin{array}{l}\text { 3-D nonlinear transient } \\
\text { field in solid magnetic } \\
\text { plate under } \\
\text { multi-harmonic and/or } \\
\text { DC-biasing excitations. }\end{array}$ & $\begin{array}{l}\text { Magnetic loss in } \\
\text { solid magnetic } \\
\text { components } \\
\text { under extreme } \\
\text { conditions. }\end{array}$ & $\begin{array}{l}\text { Upgraded } \\
\mathrm{P} 21^{0}-\mathrm{B} \text { with } \\
\text { magnetic flux } \\
\text { compensation. }\end{array}$ \\
\hline $\mathrm{P} 21^{\mathrm{c}}-\mathrm{M} 1^{+}$ & $\begin{array}{l}\text { 3-D nonlinear transient } \\
\text { field in laminated sheets } \\
\text { under multi-harmonic } \\
\text { and/or DC-biasing } \\
\text { excitations. }\end{array}$ & $\begin{array}{l}\text { Magnetic loss in } \\
\text { laminated } \\
\text { magnetic } \\
\text { components } \\
\text { under extreme } \\
\text { conditions. }\end{array}$ & $\begin{array}{l}\text { Ungraded } \\
\text { P21 } 11^{\mathrm{C}} \text {-M1 with } \\
\text { different types } \\
\text { of laminated } \\
\text { sheets. }\end{array}$ \\
\hline
\end{tabular}




\section{P21-Based Benchmarking Notes}

\subsection{Finite Element Model for Lamination Configuration}

In order to reduce the electromagnetic computation costs and obtain the solutions very efficiently, a number of homogenization methods for the lamination structures, such as the transformer core and the magnetic shields, have been proposed [34-38]. The following benchmarking model aims to deal with the standard iron loss and additional iron loss based on a simple model [12].

The simplified finite element model of the laminated GO silicon sheets has the following characteristics:

1) Treatment of electric anisotropy

Pattern 1: Modeling the first few laminations individually and modeling the rest as bulk; the 3-D eddy currents flow in the individual laminations and the 2-D eddy currents are limited in each lamination in the bulk region where the anisotropic conductivity is used, see Fig. 4(a).

Pattern 2: Fine meshing within a thin surface layer, and coarse meshing inside the bulk. In the entire conducting domain, the anisotropic conductivity is assumed. See Fig.4 (b).

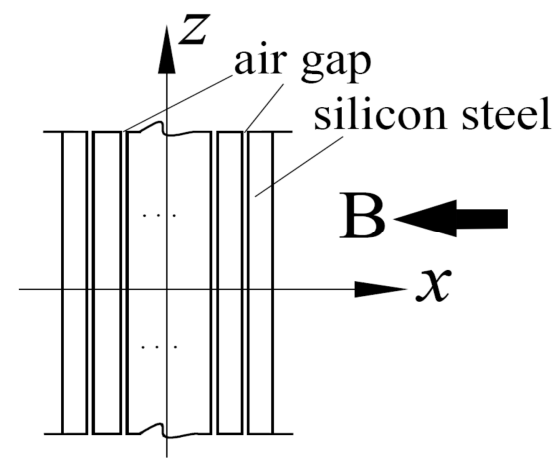

(a) Pattern 1. (With interlaminar air gap)

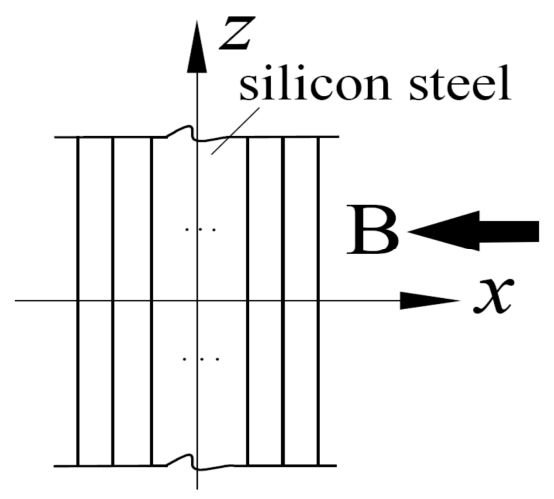

(b) Pattern 2. (With electric anisotropy)

Figure 4. Simplification of laminated sheets.

2) Treatment of magnetic anisotropy

The resulting magnetic field inside the laminated sheet is almost in one direction (along the z-axis), making it a weak magnetic anisotropy problem, and the orthogonal anisotropic permeability is assigned to all the laminations.

\subsection{Eddy Current Analysis}

The well-established eddy current solvers, based on various potential sets, have been developed and applied in the computational electromagnetics research and industrial applications [29-33]. In the method based on the $T-\Omega$ potential set, used by MagNet, the software used for the work in this paper, the magnetic field is represented as the sum of two parts, i.e., the gradient of a scalar potential $\Omega$ and $T$. In the conductors, an additional vector field is represented with vector-edge elements. As a result, the solution vector consists of the magnetic scalar potential at the nodes plus edge-degrees of freedom associated with the current flow in solid conductors. The $T-\Omega$ based solver does not run into the convergence and instability issues associated with other formulations [32]. The governing equation in the eddy current region, and in the presence of anisotropic and nonlinear materials, is given by (1),

$$
\nabla \times\left([\sigma]^{-1} \nabla \times \mathrm{T}\right]+[\mu] \frac{\partial(\mathrm{T}-\nabla \Omega)}{\partial t}=0
$$

The anisotropic and nonlinear permeability $[\mu]$ in (1) can be represented by (2)

$$
[\mu]=\left[\begin{array}{lll}
\mu_{0} /\left(1-c_{p}\right) & & \\
& C_{p} \mu_{y} & \\
& & C_{p} \mu_{z}
\end{array}\right]
$$

where $C_{p}$ is the packing factor.

The anisotropic conductivity $[\sigma]$ of the sheets can be dealt with as

$$
[\sigma]=\left[\begin{array}{lll}
c_{p} \sigma_{x} & & \\
& c_{p} \sigma_{y} & \\
& & c_{p} \sigma_{z}
\end{array}\right]
$$

where $\sigma_{\mathrm{y}}=\sigma_{\mathrm{z}}=\sigma_{\mathrm{yz}}$ in the sheets, while $\sigma_{\mathrm{x}}$ is expressed as

$$
\sigma_{x}=\left\{\begin{array}{c}
\approx 0(2 D \text { eddy current region }) \\
\text { assigned ( } 3 D \text { eddy current region })
\end{array}\right.
$$

The iron loss and flux generated in the GO laminations are computed based on the field results, as part of the post processing operation. The additional iron loss $P_{a}$, caused by the flux entering normal to the laminated sheets, is not included in the measured total iron loss (by using standard magnetic property measurement methods), however, it cannot be neglected. As a practical solution, the total iron loss $P_{t}$, referred to as standard iron loss, can be divided into two parts, i.e.,

$$
\mathrm{P}_{\mathrm{t}}=\mathrm{P}_{\mathrm{s}}+\mathrm{P}_{\mathrm{a}}
$$

where $P_{s}$ can be numerically computed based on the 3-D field solution $\left(\mathrm{B}_{\mathrm{m}}^{\mathrm{e}}\right)$, the measured standard loss curve $B_{m}-W_{t}$, and the elements volumes, and then summed up, as shown in (6), 


$$
\mathrm{P}_{\mathrm{s}}=\sum_{\mathrm{e}} \mathrm{P}_{\mathrm{s}}^{\mathrm{e}}\left(\mathrm{W}_{\mathrm{t}}, \mathrm{B}_{\mathrm{m}}^{\mathrm{e}}\right) \cdot \mathrm{V}^{\mathrm{e}}
$$

where $\mathrm{P}_{\mathrm{s}}^{\mathrm{e}}$ and $V^{\mathrm{e}}$ are the total specific loss and volume of each element in the lamination-layers.

While $P_{a}$ can be calculated based on the induced eddy current field solution $\boldsymbol{J}$ flowing in the lamination-layers, with anisotropic conductivity $\sigma$ according to equation (7),

$$
\mathrm{P}_{\mathrm{a}}=\int \frac{J \cdot J}{\sigma} \mathrm{dv}
$$

\subsection{On Magnetic Property Modeling}

Both, keeping track of advanced material modeling technologies and promoting large-scale applications, using the existing material property data, from the point of view of industrial application, are really important.

(a) A bottleneck problem of industrial application

The material property modeling is one of the key topics of the engineering electromagnetics. In the author's opinion, it is still a bottleneck-problem of industrial applications. This is because the measurement conditions used in measuring the material properties are standard, using standard equipment, such as the Epstein frame, SST, or other equipment used for obtaining vector magnetic properties [17, 20]. However, the working conditions that the components in a device are subjected to are not standard.

Up to now, the material property data provided by the material manufacturers are one-dimensional, but the field problems in the real products are three-dimensional. So another problem to figure out is how to use the existing property data when solving the real problems?

(b) Combination of material modeling and numerical computation

The majority of the current electromagnetic-thermal analysis software can access the one-dimensional or the so-called orthogonal-anisotropic property data. The software must be upgraded if the vector property data of the material is to be used.

(c) Improvement of magnetic property modeling technology

For many years, the standard testing equipment have been used for the measurement of the magnetic material property. There is a need for an extension to the measurement function and upgrades of the measurement values, for example, using the Epstein frame to measure the different types of B-H curves $\left(\mathrm{B}_{\mathrm{m}}-\mathrm{H}_{\mathrm{m}}\right.$ and $\left.\mathrm{B}_{\mathrm{m}}-\mathrm{H}_{\mathrm{b}}\right)$, or when the mean path length of the Epstein depends on many factors and is not a constant value $[39,40]$.

\subsection{Effect of B-H Properties on Iron Loss and Flux}

\subsubsection{Different $\mathrm{B}-\mathrm{H}$ Curves}

Two kinds of B-H curves, namely $\mathrm{B}_{\mathrm{m}}-\mathrm{H}_{\mathrm{m}}$ and $\mathrm{B}_{\mathrm{m}}-\mathrm{H}_{\mathrm{b}}$, are currently used in electromagnetic field computation [13]. The $\mathrm{B}_{\mathrm{m}}-\mathrm{H}_{\mathrm{m}}$ curve takes the maximum values of both the flux density $\left(\mathrm{B}_{\mathrm{m}}\right)$ and the magnetic field strength $\left(\mathrm{H}_{\mathrm{m}}\right)$ within a cycle. Generally, $B_{m}$ and $H_{m}$ cannot achieve the maximum value at the same time inside the magnetic steel due to the eddy current, especially at low flux density, as shown in Fig.5. Thus there is another magnetic field strength $\mathrm{H}_{b}$ corresponding to the maximum value of the flux density $B_{m}$, i.e. $\mathrm{B}_{\mathrm{m}}-\mathrm{H}_{\mathrm{b}}$ curve, see Fig.5. The eddy current becomes zero at the instant when the flux becomes the maximum, therefore, $\mathrm{B}_{\mathrm{m}}-\mathrm{H}_{\mathrm{b}}$ curve can be referred to as a dc $\mathrm{B}-\mathrm{H}$ curve.

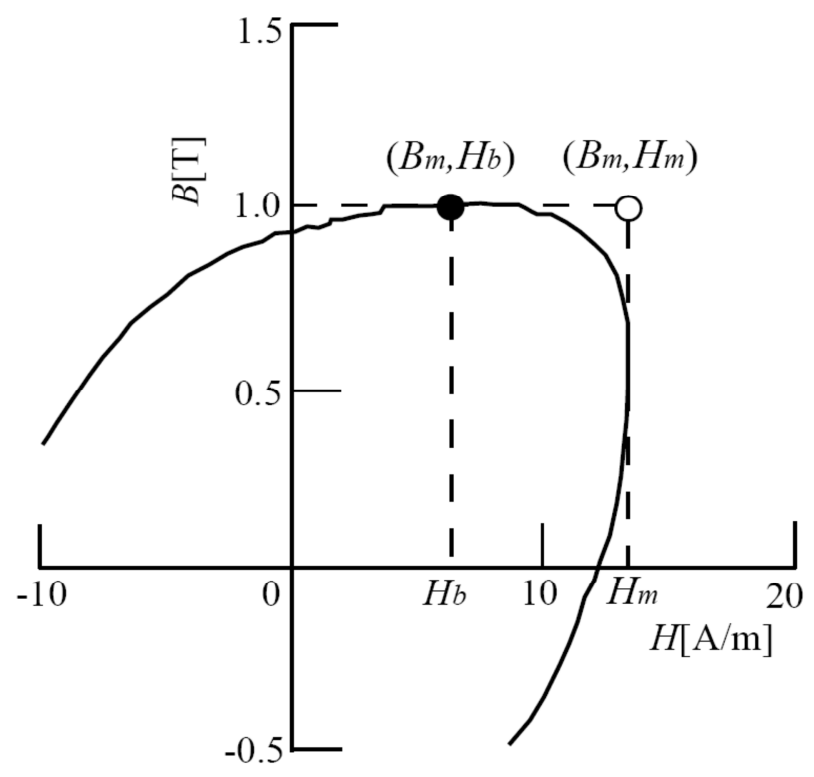

(a) $\mathrm{B}_{\mathrm{m}}=1.0 \mathrm{~T}$

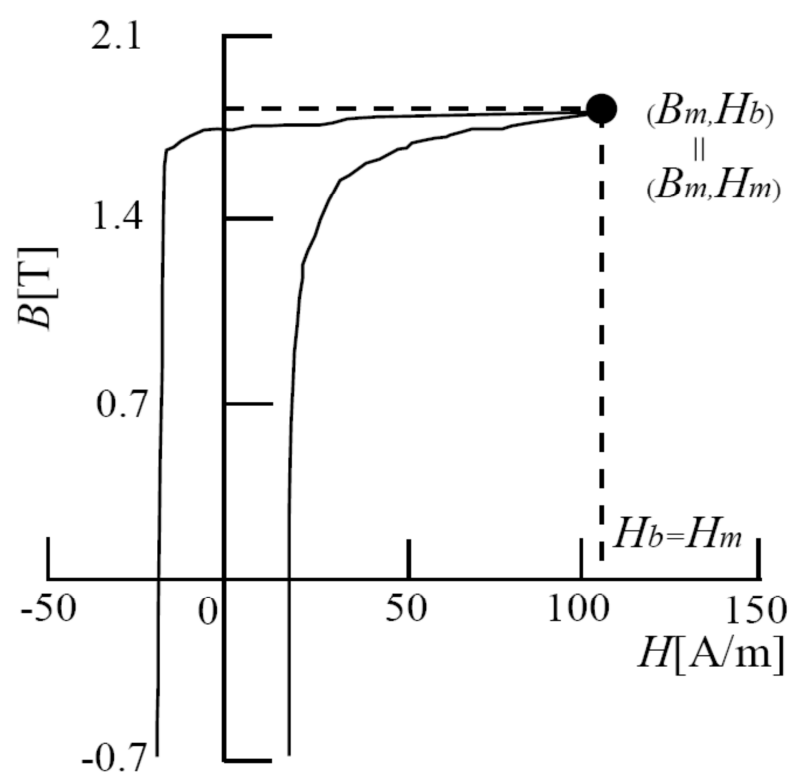

(b) $\mathrm{B}_{\mathrm{m}}=1.8 \mathrm{~T}$

Figure 5. Definition of $B_{m}, H_{m}$ and $H_{b}(30 P 105, f=50 \mathrm{~Hz})$.

Fig.6 shows the examples of forming $\mathrm{B}_{m}-\mathrm{H}_{m}$ and $\mathrm{B}_{\mathrm{m}}-\mathrm{H}_{b}$ curves based on hysteresis loops (30P105), and Fig.7 demonstrates the measured B-H curve family (SST with $\mathrm{H}$ coil) at different frequencies. Both Fig. 6 and Fig.7 indicate that the $\mathrm{B}_{\mathrm{m}}-\mathrm{H}_{\mathrm{b}}$ curves at around a commercial frequency (e.g., $50 \mathrm{~Hz}$ ) 
are similar to the dc B-H curve at low frequency $(0.01 \mathrm{~Hz})$, but $\mathrm{B}_{\mathrm{m}}-\mathrm{H}_{\mathrm{m}}$ curves are different from the quasi dc B-H curve.

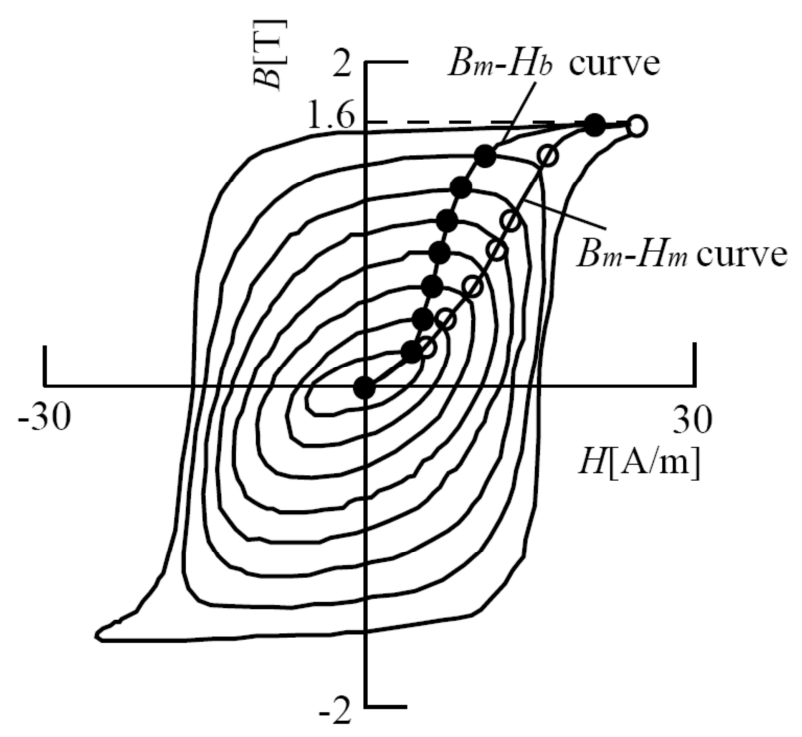

(a) $\mathrm{f}=50 \mathrm{~Hz}$

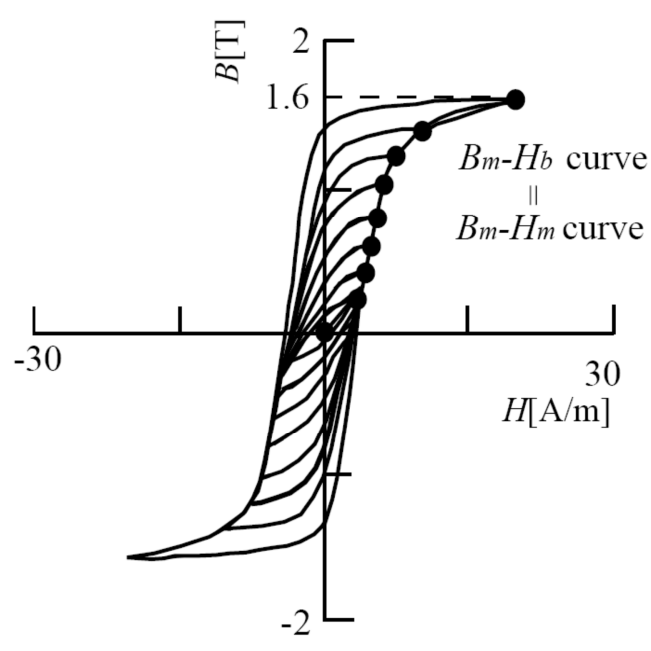

(b) $\mathrm{f}=0.01 \mathrm{~Hz}$

Figure 6. Hysteresis loops at different frequencies (30P105).

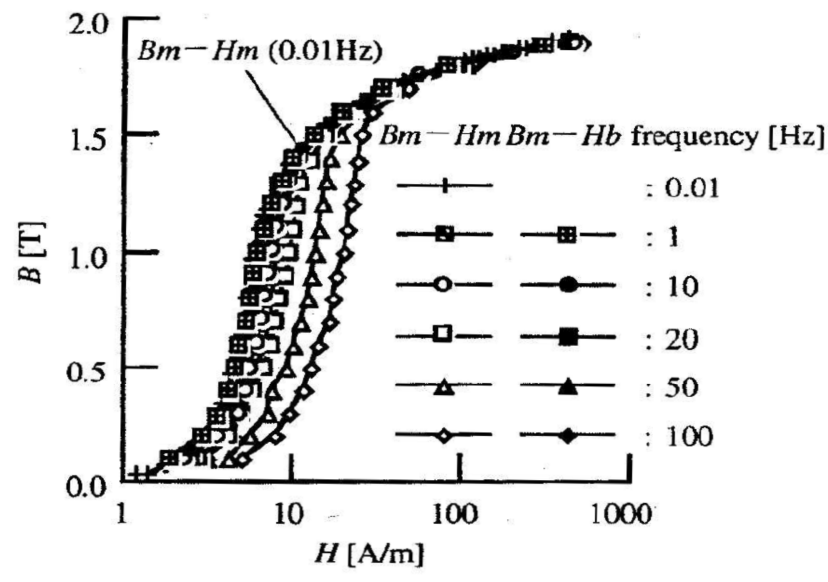

Figure 7. Comparison of B-H curves (30P105).

\subsubsection{Different Sampling of GO Silicon Steel Sheets}

The $\mathrm{B}-\mathrm{H}$ curves $\left(\mathrm{B}_{\mathrm{m}}-\mathrm{H}_{\mathrm{m}}\right.$ and $\left.\mathrm{B}_{\mathrm{m}}-\mathrm{H}_{\mathrm{b}}\right)$ and the specific loss curve $\left(\mathrm{W}_{\mathrm{t}}-\mathrm{B}_{\mathrm{m}}\right)$, measured at different sampling angles to the rolling direction of the GO steel sheet (30P120) and at different frequencies using the Epstein frame, are shown in Fig. 8 [13].

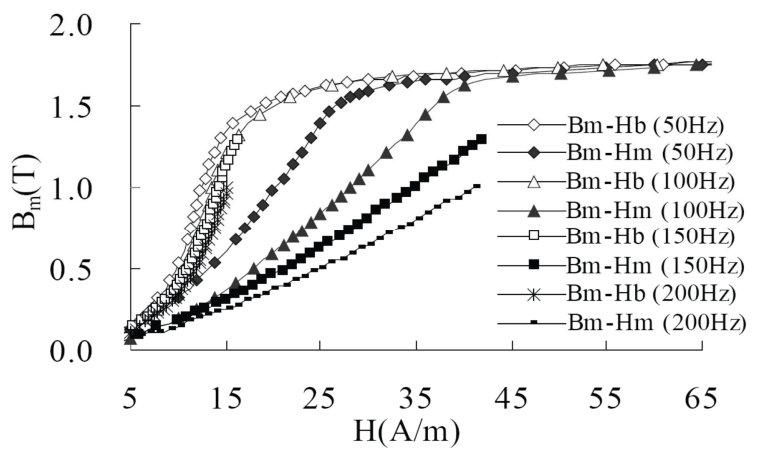

(a) B-H curves ( $0^{\circ}$ to rolling direction).

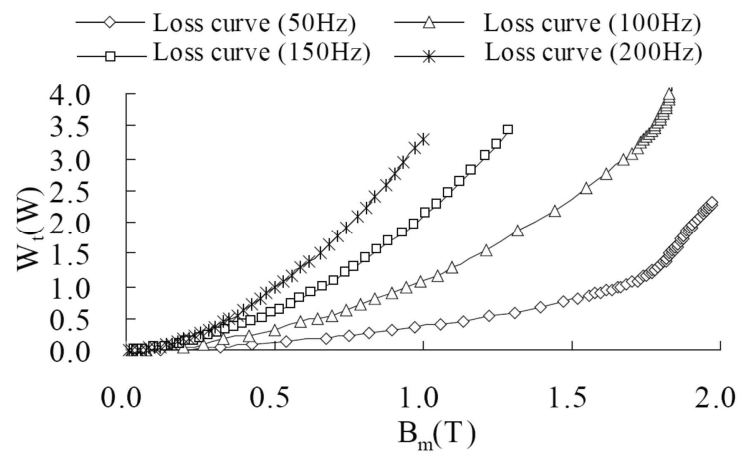

(b) $\mathrm{B}_{\mathrm{m}}-\mathrm{W}_{\mathrm{t}}$ curves $\left(0^{\circ}\right.$ to rolling direction).

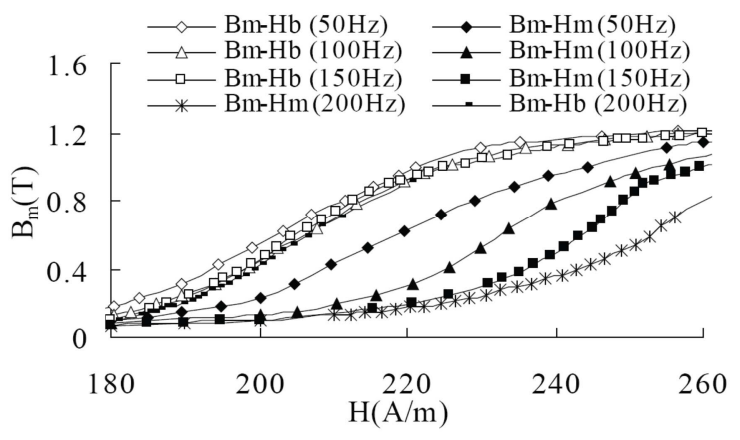

(c) B-H curves ( $90^{\circ}$ to rolling direction).

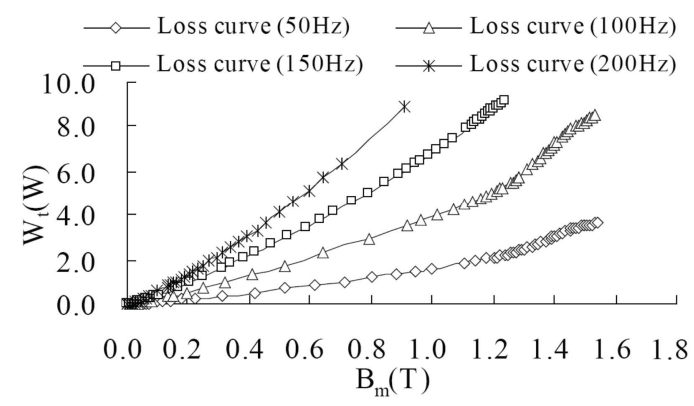

(d) $\mathrm{W}_{\mathrm{t}}-\mathrm{B}_{\mathrm{m}}$ curves $\left(90^{\circ}\right.$ to rolling direction).

Figure 8. $B-H$ and $B_{m}-W$ curves of $30 P 120$. 
A comparison between the $\mathrm{B}-\mathrm{H}$ curves, i.e., $\mathrm{B}_{\mathrm{m}}-\mathrm{H}_{\mathrm{m}}$ and $\mathrm{B}_{\mathrm{m}}-\mathrm{H}_{\mathrm{b}}$, measured by using Epstein frame and SST respectively, is given. See Fig. 9.

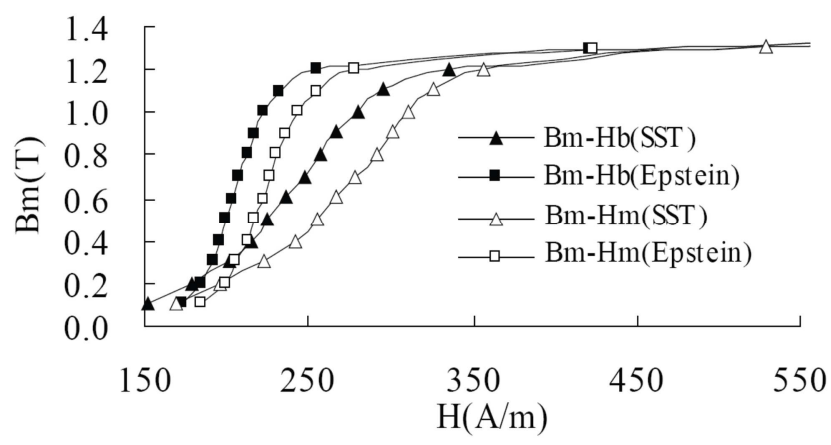

Figure 9. $B-H$ curves $\left(90^{\circ}\right.$ to rolling direction) measured using SST and Epstein frame (30P120).

\subsubsection{Test Models and Results}

Table 7. Specification of test models.

\begin{tabular}{lllll}
\hline Models & $\begin{array}{l}\text { Magnetic plate } \\
\text { of } \mathbf{1 0} \text { mm thick }\end{array}$ & $\begin{array}{l}\text { GO silicon } \\
\text { sheets }\end{array}$ & $\begin{array}{l}\text { Sheet-coil } \\
\text { distance } \\
(\mathbf{m m})\end{array}$ & $\begin{array}{l}\text { Sheet size } \\
(\mathbf{m m})\end{array}$ \\
\hline $\mathrm{T} 1$ & Without & $30 \mathrm{P} 120$ & 15.0 & $500 \times 500$ \\
$\mathrm{~T} 2$ & Without & $30 \mathrm{P} 120$ & 12.0 & $80 \times 458(3$ sets $)$ \\
$\mathrm{P} 21^{\mathrm{c}}$-M1 & With & $30 \mathrm{RGH} 120$ & 12.0 & $270 \times 458$ \\
$\mathrm{P} 21^{\mathrm{c}}$-M2 & With & 30RGH120 & 12.0 & $80 \times 458(3$ sets $)$ \\
\hline
\end{tabular}

To examine the effects of the different B-H representations on the iron loss and flux inside the lamination, two test models have been proposed, i.e. Model T1 and Model T2, which are derived from the benchmark Model P2 $1^{\mathrm{c}}-\mathrm{M} 1$ and $\mathrm{P} 21^{\mathrm{c}}-\mathrm{M} 2$ of Problem 21 Family, respectively. A brief comparison among the benchmark models and the newly proposed Problem 21-based test models is shown in Table 7.

In Model T1, only six silicon steel sheets of $500 \times 500 \mathrm{~mm}$ (30P120) are driven by a twin AC source (50 to $200 \mathrm{~Hz}$ ), a 3-D excitation, see Fig. 10 (a). The purpose of Model T2 is to show the effect of the division of the wide sheets on the reduction of iron loss, see Fig. 10 (b).

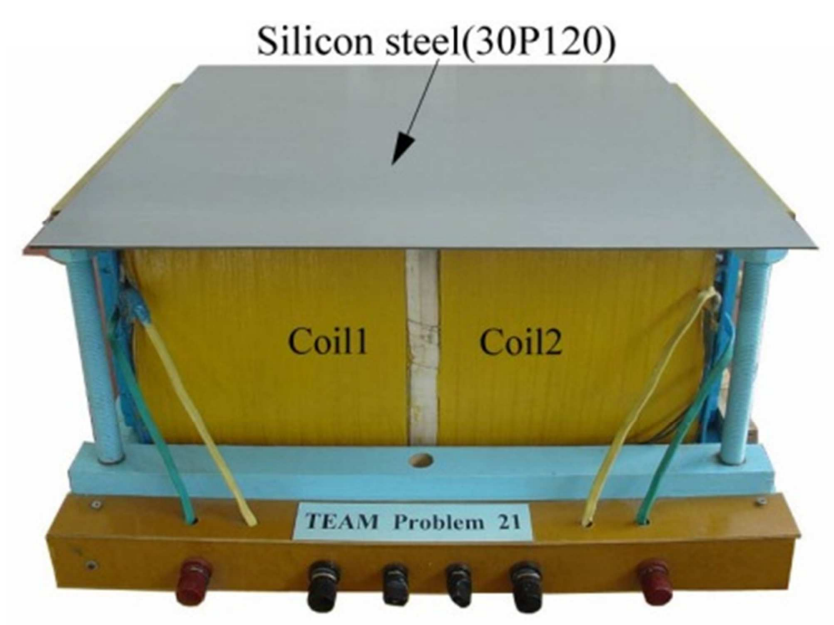

(a) Model T1.

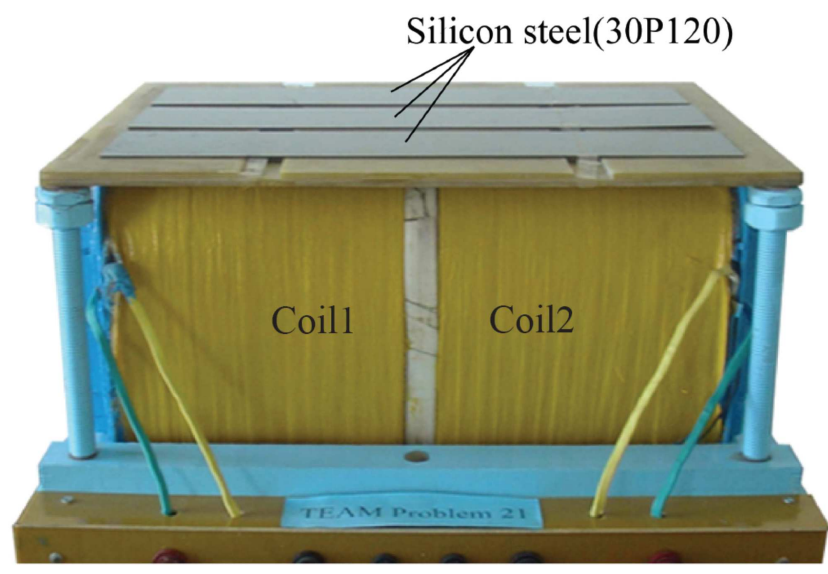

(b) Model T2.

Figure 10. Models $T 1$ and $T 2$.

\subsubsection{Discussion}

According to the pre-measurement results obtained by the authors, the saturation level of the laminated sheets is not so high, especially at lower excitations. Both the time harmonic (TH) and the time stepping (TS) solvers of the $\boldsymbol{T}$ - $\Omega$-based MagNet, Infolytica, are used to solve the 3-D eddy current problem. Table 8 shows the calculated and measured results of the total iron loss $P_{t}$ of Model T1.

All the calculated results, using different B-H curves and different solvers, indicate that the use of TH solver and $B_{m}-H_{m}$ curve can offer better results when compared to measurement. This is, because the element-permeability is dependent on the quasi-maximum values of $\mathrm{B}$ and $\mathrm{H}$ within a cycle in the $\mathrm{TH}$ solver. On the contrary, in the case of the TS solver, $\mathrm{B}_{\mathrm{m}}-\mathrm{H}_{\mathrm{b}}$ curve can offer better results. This is, because in the TS solver the element-permeability is determined according to the instantaneous values of $\mathrm{B}$ and $\mathrm{H}$ at an instant. As a result, a more precise analysis is possible by the time stepping method using the $B_{m}-H_{b}$ curve, which is almost the same as the dc B-H curve.

Table 8. Total iron loss results (Model T1).

\begin{tabular}{|c|c|c|c|c|c|}
\hline \multirow{3}{*}{$\begin{array}{l}\text { Current (A, } \\
\text { rms, 50Hz) }\end{array}$} & \multicolumn{4}{|c|}{ Calc. (W) } & \multirow{3}{*}{$\begin{array}{l}\text { Meas. } \\
(W)\end{array}$} \\
\hline & \multicolumn{2}{|c|}{ TH solver/Pattern 1} & \multicolumn{2}{|c|}{ TS solver/Pattern 2} & \\
\hline & $\mathbf{B}_{m}-H_{b}$ & $\mathbf{B}_{\mathrm{m}}-\mathrm{H}_{\mathrm{m}}$ & $\mathbf{B}_{\mathrm{m}}-\mathrm{H}_{\mathrm{b}}$ & $\mathbf{B}_{\mathrm{m}}-\mathrm{H}_{\mathrm{m}}$ & \\
\hline 10 & 2.61 & 2.74 & 2.54 & 2.35 & 2.52 \\
\hline 15 & 7.26 & 7.89 & 6.66 & 6.24 & 7.12 \\
\hline 20 & 12.74 & 14.14 & 13.37 & 12.65 & 13.7 \\
\hline 25 & 20.31 & 22.47 & 23.68 & 24.01 & 23.8 \\
\hline
\end{tabular}

Table 9 shows the contributions of additional iron loss $P_{a}$ and standard specific iron loss $P_{s}$ to the total iron loss $P_{t}$, using different solvers and/or different kinds of B-H curves. Table 9 also indicates that $P_{s}$ calculated using $\mathrm{B}_{\mathrm{m}}-\mathrm{H}_{\mathrm{b}}$ curve is larger than that using the $B_{m}-H_{m}$ curve. This is, because the permeability taken from $B_{m}-H_{b}$ curve is higher than that taken from $\mathrm{B}_{\mathrm{m}}-\mathrm{H}_{\mathrm{m}}$ curve. See Fig. 11 .

However, from the calculated results, $P_{a}$ has a different tendency, using different B-H curve and/or different (TH or TS) solver. 
Table 9. Components of iron loss (Model T1).

\begin{tabular}{|c|c|c|c|c|c|c|c|c|}
\hline \multirow{3}{*}{ Current (A, rms, 50Hz) } & \multicolumn{4}{|c|}{ TH solver (W) } & \multicolumn{4}{|c|}{ TS solver (W) } \\
\hline & \multicolumn{2}{|l|}{$\mathbf{B}_{\mathrm{m}}-\mathbf{H}_{\mathrm{b}}$} & \multicolumn{2}{|l|}{$\mathbf{B}_{\mathrm{m}}-\mathbf{H}_{\mathrm{m}}$} & \multicolumn{2}{|l|}{$\mathbf{B}_{\mathrm{m}}-\mathbf{H}_{\mathrm{b}}$} & \multicolumn{2}{|c|}{$\mathbf{B}_{\mathrm{m}}-\mathbf{H}_{\mathrm{m}}$} \\
\hline & $\boldsymbol{P}_{a}$ & $\boldsymbol{P}_{s}$ & $\boldsymbol{P}_{a}$ & $P_{s}$ & $P_{a}$ & $P_{s}$ & $P_{a}$ & $\boldsymbol{P}_{s}$ \\
\hline 10 & 1.53 & 1.08 & 1.81 & 0.93 & 1.73 & 0.81 & 1.72 & 0.63 \\
\hline 15 & 5.50 & 1.76 & 6.35 & 1.54 & 5.20 & 1.46 & 5.12 & 1.12 \\
\hline 20 & 10.44 & 2.31 & 12.07 & 2.07 & 11.15 & 2.22 & 10.95 & 1.70 \\
\hline 25 & 17.19 & 3.12 & 19.89 & 2.58 & 21.22 & 2.46 & 21.59 & 2.42 \\
\hline
\end{tabular}

The calculated results by both the TH and TS solvers show that the iron loss is mainly concentrated in a few layers on the side facing the exciting source, and goes down with the increase of layer-number going from 1 to 6 , at 20A(50Hz) for Model T1, as shown in Fig. 9.

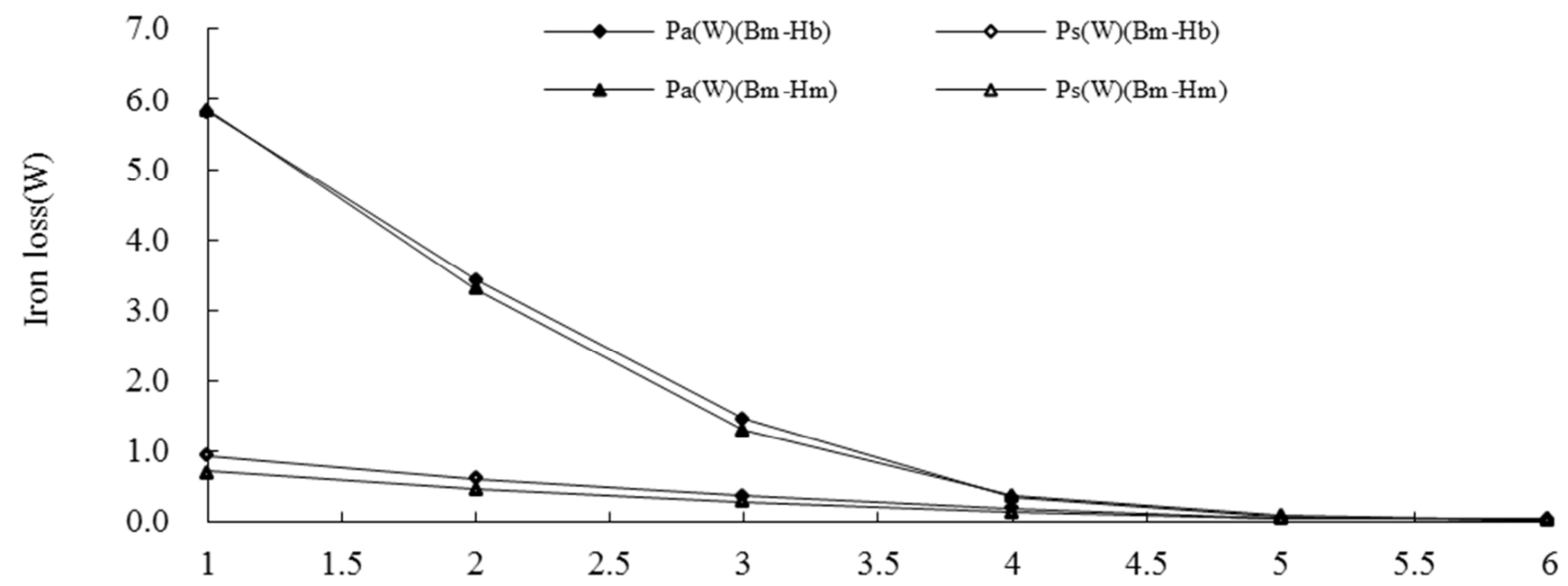

Number of layers

Figure 11. Iron loss distribution in layers (calculated by TS solver, Model T1, at 50Hz).

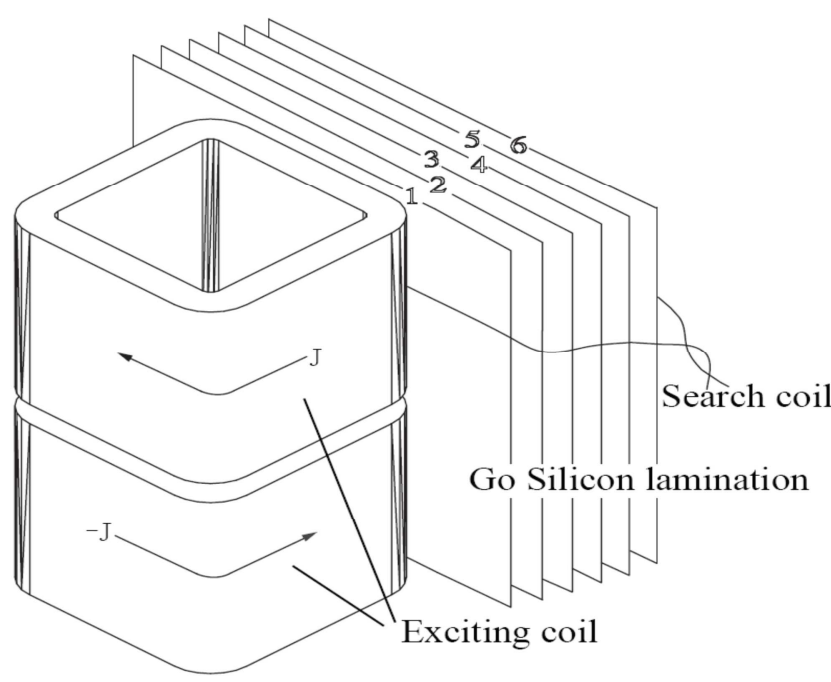

(a) Locations of search coils (sketch)

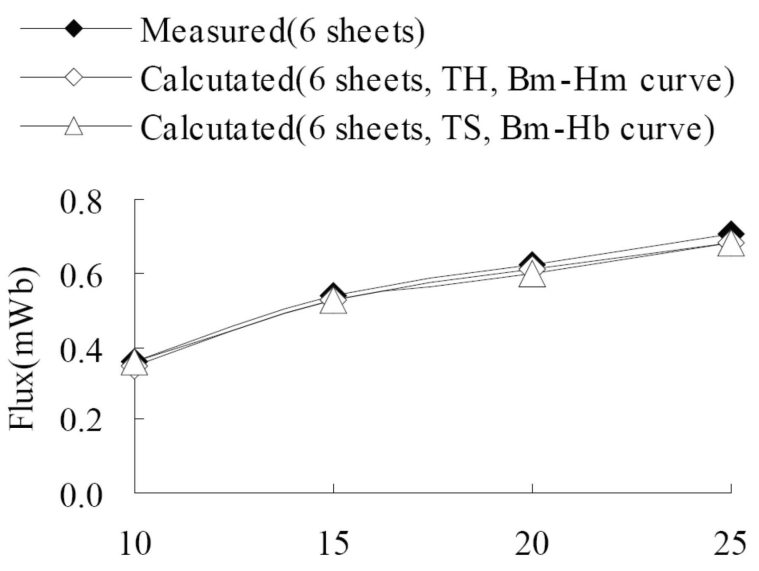

Exciting current $(\mathrm{A}, \mathrm{rms}, 50 \mathrm{~Hz})$

(b) Magnetic flux in GO sheets

Figure 12. Magnetic flux inside GO laminated sheets (Model T1, 50Hz).

To determine the magnetic flux inside the laminated sheets, search coils are set up in Model T1; see Fig. 12(a). The magnetic fluxes, at the prescribed positions of the laminations under the different exciting currents, are calculated. Either TH 
solver and $B_{m}-H_{m}$ curve or TS solver and $B_{m}-H_{b}$ curve are applied. The calculated results agree well with the measured ones. See Fig. 12(b).

In Model T2, the iron loss produced in the three sets of the narrow GO silicon steel sheets of $80 \times 458 \mathrm{~mm}$, which are placed in parallel, is considerably lower compared to that of Model T1 for the same exciting currents.

Fig. 13 shows the calculated and the measured results of iron loss of Model T2 at 10A, under a frequency range from 50 to $200 \mathrm{~Hz}$. The results also indicate that the iron loss increases with the exciting frequency.

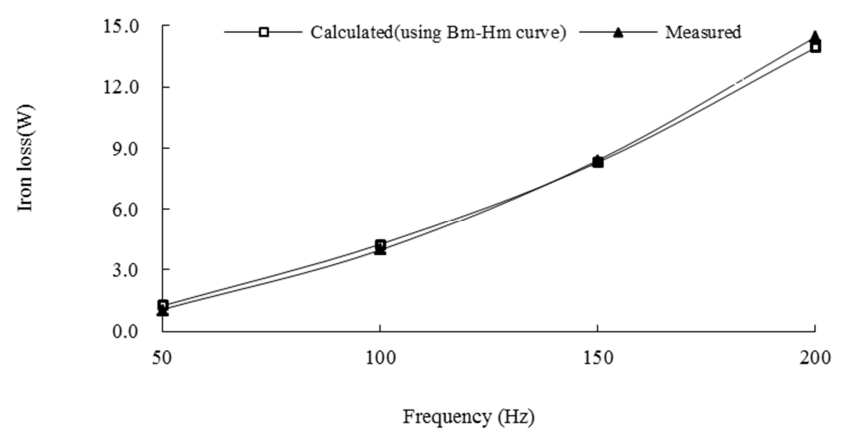

Figure 13. Iron loss varying with frequency (calculated by TH solver using $B_{m}-H_{m}$ curve, Model T2).

Following is a very brief summary:

1) The examination of the effect of the different B-H curves (obtained by different means and data access modes and at different frequencies) on the iron loss and flux in GO silicon steel laminations is carried out. The numerical modeling results of the iron loss and flux based on the test models are in practical agreement with the measured ones.

2) All the numerical modeling results suggest that the $B_{m}-H_{b}$ curve is desirable for the use in the transient solver, but the combination of the $\mathrm{B}_{\mathrm{m}}-\mathrm{H}_{\mathrm{m}}$ curve and the time harmonic solver is also available for the problem with lower saturation levels.

3) The additional iron loss $\left(P_{a}\right)$, due to the normal flux, exponentially drops from the surface facing the exciting source to the opposite side of the laminated sheets. On the other hand, the specific iron loss $\left(P_{s}\right)$ generated by the parallel flux drops slowly compared to $P_{a}$.

\section{Concluding Remarks}

The progress of TEAM Problem 21 Family and long-term P21-based benchmarking are briefly reviewed, and a selected set of benchmarking results are presented.

The magnetic loss and flux inside both the solid and laminated components are numerically computed using different solvers based on different potential sets and measured using well-established experimental setups.

The effect of the variation in the B-H representations used in different solvers on the iron loss and flux in laminated sheets are examined in detail.

As the future research project, the Problem 21 Family is being extended to cover the modeling and computation issues that a device experiences when under extreme excitation conditions.

\section{Acknowledgement}

The authors would like to thank the heads and all the colleagues of R \& D Center, Baobian Electric Group, for their cooperation, support and help in the long-term P21-based experiment and numerical modeling, and thank the ICS for all the approved updates of TEAM P21. Specially, here and now the authors would express their grief to the late Prof. Norio Takahashi for his co-research for many years.

\section{References}

[1] TEAM Benchmark Problems. [Online]. available: www.compumag.org/TEAM.

[2] IEEE Std 1597.1 ${ }^{\mathrm{TM}}$-2008: IEEE Standard for validation of computational electromagnetics computer modeling and simulations.

[3] Z. Cheng, Q. Hu, S. Gao, Z. Liu, C. Ye, M. Wu, J. Wang, and $\mathrm{Z} . \mathrm{Hu}$, "An engineering-oriented loss model (Problem 21)," Proc. of the international TEAM Workshop, Miami, pp.137-143, 1993.

[4] Z. Cheng, N. Takahashi, B. Forghani, X. Wang, et al, "Extended progress in TEAM Problem 21 family," COMPEL, 33, 1/2, pp.234-244, 2014.

[5] Z. Cheng, N. Takahashi, B. Forghani, and Y. Wang, "Engineering-oriented benchmarking and application-based magnetic material modeling in transformer research", Presented at the International Colloquium Transformer Research and Asset Management(invited), Dubrovnik, Croatia, May $16-18,2012$.

[6] Z. Cheng, Q. Hu, N. Takahashi, and B. Forghani, "Stray-field loss modeling in transformers," International Colloquium Transformer Research and Asset Management, Cavtat, Croatia, Nov.12-14, 2009.

[7] N. Takahashi, T. Sakura and Z. Cheng, "Nonlinear analysis of eddy current and hysteresis losses of 3-D stray field loss model (Problem 21)," IEEE Trans. Magn., vol.37, no.5, pp.3672-3675, 2001.

[8] Z. Cheng, R. Hao, N. Takahashi, Q. Hu, and C. Fan, "Engineering-oriented benchmarking of Problem 21 family and experimental verification," IEEE Trans. Magn., vol. 40, no.2, pp.1394-1397, 2004.

[9] Z. Cheng, N. Takahashi, S. Yang, T. Asano, Q. Hu, S. Gao, X. Ren, H. Yang, L. Liu, and L. Gou, "Loss spectrum and electromagnetic behavior of Problem 21 family", IEEE Trans. Magn., vol.42, no.4, pp.1467-1470, 2006.

[10] Z. Cheng, N. Takahashi, S. Yang, C. Fan, M. Guo, L. Liu, J. Zhang, and S. Gao, "Eddy current and loss analysis of multi-steel configuration and validation," IEEE Trans. Magn., vol.43, no.4, pp.1737-1740, 2007.

[11] Z. Cheng, N. Takahashi, B. Forghani, G. Gilbert, J. Zhang, L. Liu, Y. Fan, X. Zhang, Y. Du, J. Wang, and C. Jiao, "Analysis and measurements of iron loss and flux inside silicon steel laminations," IEEE Trans. Magn.,vol.45, no.3, pp.1222-1225, 2009. 
[12] Z. Cheng, N. Takahashi, B. Forghani, et al, "Effect of excitation patterns on both iron loss and flux in solid and laminated steel configurations," IEEE Trans. Magn., vol.46, no.8, pp.3185-3188, 2010.

[13] Z. Cheng, N. Takahashi, B. Forghani, et al, "Effect of variation of B-H properties on loss and flux inside silicon steel lamination," IEEE Trans. Magn., vol.47, no.5, pp.1346-1349, 2011.

[14] Z. Cheng, N. Takahashi, B. Forghani, L. Liu, Y. Fan, T. Liu, J. Zhang, and X. Wang, "3-D finite element modeling and validation of power frequency multi-shielding effect," IEEE Trans. Magn., vol.48, no.2, pp.243-246, 2012.

[15] Z. Cheng, N. Takahashi, B. Forghani, et al, "Electromagnetic and Thermal Field Modeling and Application in Electrical Engineering," Science Press (in Chinese), ISBN 978-7-03-023561-9, Beijing, 2009.

[16] A. J. Moses, "Characterisation and performance of electrical steels for power transformers operating under extremes of magnetisation conditions," International Colloquium Transformer Research and Asset Management, Cavtat, Croatia, Nov.12-14, 2009.

[17] M. Enokizono, H. Shimoji, A. Ikariga, et al, "Vector magnetic characteristic analysis of electrical machines," IEEE Trans. Magn., vol.41, no.5, pp.2032-2035, 2005.

[18] K. Fujiwara, T. Adachi, and N. Takahashi, "A proposal of finite-element analysis considering two-dimensional magnetic properties," IEEE Trans. Magn., vol.38, no.2, pp.889-892, 2002.

[19] H. Nishimoto, M. Nakano. K. Fujiwara, and N. Takahashi, "Effect of frequency on magnetic properties," Papers of Technical Meeting on Magnetics, IEE Japan, MAG-98-56, 1998 (in Japanese).

[20] J. Zhu, J. J. Zhong, Z. W. lin, et al, "Measurement of magnetic properties under 3-D magnetic excitations," IEEE Trans. Magn., vol.39, no.5, pp. 3429-3431, 2003.

[21] J. Turowski, M. Turowski, and M. Kopec, "Method of three-dimensional network solution of leakage field of three-phase transformers," IEEE Trans. Magn., vol. 26, no. 5, pp. 2911-2919, 1990

[22] N. Takahashi, S. Nakazaki, and D. Miyagi, "Optimization of electromagnetic and magnetic shielding using ON/OFF method," IEEE Trans. Magn., vol.46, no.8, pp.3153-3156, 2010 .

[23] M. Horii, N. Takahashi, and J. Takehara, "3-D optimization of design variables in $\mathrm{x}-, \mathrm{y}-$, and $\mathrm{z}$-directions of transformer tank shield model," IEEE Trans. Magn., vol.37, no.5, pp.3631-3634, 2001.

[24] J. Turowski, X. M. Lopez-Fernandez, A. Soto, and D. Souto, "Stray losses control in core- and shell-type transformers," Advanced Research Workshop on Transformers, Baiona, Spain, 29-31 Oct., 2007.

[25] K. V. Namjosji and P. P. Biringer, "Efficiency of eddy current shielding of structural steel surrounding large currents: a circuit approach," IEEE Trans. Magn., vol.27, no.6, pp.5417-5419, 1991.
[26] R. Tang, Y. Li, F. Lin, and L. Tian, "Resultant magnetic fields due to both windings and heavy current leads in large power transformers," IEEE Trans. Magn., vol.32, no.3, pp.1641-1644, 1996.

[27] R. M. D. Vecchio, "Eddy current losses in a conducting plate due to a collection of bus bars carrying currents of different magnitudes and phases," IEEE Trans. Magn., vol.39, no.1, pp.549-552, 2003.

[28] Z. Cheng, B. Forghani, Y. Liu, Y. Fan, T. Liu, and Z. Zhao, "Magnetic Loss inside Solid and Laminated Components under Extreme Excitations," to be published in the Special Issue (no.164022) of International Journal of Energy and Power Engineering.

[29] O. Biro and K. Preis, "Finite element analysis of 3-D eddy currents," IEEE Trans. Magn., vol.26, no.2, pp.418-423, 1990.

[30] O. Biro, K. Preis, and K. R. Richter, "Various FEM formulation for the calculation of transient 3D eddy currents in nonlinear media," IEEE Trans. Magn., vol.31, no.3, pp.1307-1312, 1995.

[31] O. Biro, K. Preis, U. Baumgartner, and G. Leber, "Numerical modeling of transformer losses," presented at International Colloquium Transformer Research and Asset Management, Cavtat, Croatia, Nov.12-14, 2009.

[32] J. P. Webb and B. Forghani, "T-Omega method using hierarchal edge elements," IEE Proc.-Sci.Meas. Technol., vol.142, no.2, 1995, pp.133-141.

[33] Z. Cheng, S. Gao, and L. Li, "Eddy Current Analysis and Validation in Electrical Engineering", Higher Education Press (in Chinese), ISBN 7-04-009888-1, Beijing, 2001.

[34] H. Kaimori, A. Kameari, and K. Fujiwara, "FEM computation of magnetic field and iron loss in laminated iron core using homogenization method," IEEE Trans. Magn., vol.43, no.4, pp.1405-1408, 2007.

[35] K. Preis, O. Biro, and I. Ticar, "FEM analysis of eddy current losses in nonlinear laminated iron cores," IEEE Trans. Magn., vol.41, no.5, pp.1412-1415, 2005.

[36] T. Kohsaka, N. Takahashi, S. Nogawa, and M. Kuwata, "Analysis of Magnetic characteristics of three-phase reactor model of grain-oriented silicon steel," IEEE Trans. Magn., vol.36, no.4, pp.1894-1897, 2000.

[37] H. Igarashi, K. Watanabe, and A. Kost, "A reduced model for finite element analysis of steel laminations," IEEE Trans. Magn., vol.42, no.4, pp.739-742, 2006.

[38] W. Zheng, and Z. Cheng, "Efficient finite element simulation for GO silicon steel laminations using inner-constrained laminar separation," IEEE Trans. Magn., vol.48, no.8, pp.2277-2283, 2012.

[39] P. Marketos, S. Zurek, and A. Moses, "A method for defining the mean path length of Epstein," IEEE Trans. Magn., vol.43, no.6, pp.2755-2757, 2007.

[40] Z. Cheng, N. Takahashi, B. Forghani, A. Moses, P. Anderson, Y. Fan, T. Liu, X. Wang, Z. Zhao, and L. Liu, "Modeling of magnetic properties of GO electrical steel based on Epstein combination and loss data weighted processing," IEEE Trans. Magn., vol.50, no.1, 6300209, 2014. 